\title{
Optimalisasi Kinerja Solar Shading Sebagai Usaha Menurunkan Solar Gain pada Bangunan
}

\author{
Cynthia Permata Dewi1 ${ }^{1}$ Joko Budi Utomo² dan Ismi Choirotin ${ }^{3}$ \\ 1 Program Studi Teknik Sipil, Universitas Islam Malang \\ ${ }^{2}$ BMKG Karangploso Malang \\ ${ }^{3}$ Program Studi Teknik Mesin, Universitas Islam Malang \\ cwit_gals@yahoo.com
}

\begin{abstract}
ABSTRAK
Penggunaan kaca sebagai material pada fasad bangunan saat ini masih dominan diaplikasikan pada bangunan-bangunan di daerah tropis. Permasalahan yang sering dihadapi adalah panas yang diterima dalam bangunan menjadi cukup tinggi. Penggunaan strategi pendinginan pasif bisa menjadi sebuah alternatif yang cukup solutif dalam mengoptimalkan komponen arsitektural bangunan itu sendiri. Tujuan dari penelitian ini adalah mengoptimalkan kinerja thermal pada bangunan melalui penggunaan material dan desain solar shading sehingga mampu menurunkan panas yang diterima oleh bangunan. Program Energyplus digunakan dalam tahapan simulasi. Aplikasi alternatif model tipe dan material diaplikasikan pada semua bukaan jendela pada bangunan studi kasus. Hasil penelitian menunjukkan bahwa solar gain eksterior window mampu berkurang sampai 52,73\% dengan penggunaan louvre beton dan louvre kayu.
\end{abstract}

Kata kunci: tipe, material, simulasi, solar gain

ABSTRACT

A glass facade is commonly used by modern building nowadays, even in the tropical area with its characteristic. Thus, buildings often face a problem with thermal comfort. Passive design strategy supposed to be considered by the architect in order to avoid inconvenience with the heat. This strategy utilized the architectural element as the tools to reach the comfort level. The aim of this study was to optimize the thermal behavior of the building itself by the modification of solar shading types and materials. EnergyPlus was used as a simulation tool in this study. The results show that solar gain exterior window can be reduced by 52,73\% by using concrete louvre and wood louvre.

Keywords: type, material, simulation, solar gain

\section{Pendahuluan}

Desain bangunan memegang peranan yang cukup penting dalam pengaruhnya terhadap penerimaan panas dan konsumsi energi yang diperlukan. Selain pengaruh pemanasan global yang terjadi saat ini, dalam kondisi mikro efek urban heat island (UHI) juga memberikan dampak yang cukup signifikan terhadap beban energi pendinginan bangunan. Sekitar $40 \%$ dari total energi yang dibutuhkan oleh sebuah bangunan, digunakan untuk kebutuhan pendinginan bangunan (Prianto, 2007).

Strategi pendinginan pasif dalam beberapa dekade ini menjadi perhatian yang cukup banyak dipertimbangkan (Dewi, 2013; Kamal, 2010; Prasetyo, 2014). Penggunaan strategi pendinginan pasif yang tepat, dapat meningkatkan performa bangunan terhadap kinerja thermal dan kebutuhan energi bangunan, khususnya energi pendinginan bangunan. Beberapa jenis metode pasif desain antara lain: shading/pembayangan, 
respon terhadap orientasi bangunan dan site, pemanfaatan ventilasi alami, dan penggunaan cahaya alami (Prasetyo, 2014).

Fasad bangunan sebagai kulit terluar dari bangunan yang berinteraksi langsung terhadap komponen iklim mikro di sekitar bangunan. Bangunan-bangunan yang tidak direncanakan dengan baik (tidak memiliki target kinerja bangunan terhadap beban energi pendinginan bangunan maupun kinerja thermal bangunan) seringkali menemui masalah dalam periode penggunaan bangunan. Kebutuhan energi listrik untuk pendinginan bangunan menjadi besar karena panas yang diterima bangunan menjadi cukup tinggi.

Pengolahan fasad bangunan yang tepat mampu memberikan efek yang cukup signifikan terhadap performa bangunan terkait dengan kondisi thermal bangunan dan kebutuhan energi bangunan (Dewi \& Bakhtiar, 2017). Penggunaan elemen pembayang matahari (solar shading) lebih efektif digunakan dalam rangka mengurangi panas yang masuk ke dalam bangunan dibanding peneduh interior (Lubab Fahmi, 2018). Material yang digunakan sebagai komponen peneduh eksterior juga akan memberikan pengaruh terhadap kinerja thermal pada bangunan (Lechner, 2007).

\section{Bahan dan Metode}

\subsection{Pembayang matahari (solar shading)}

Pembayang sinar matahari merupakan usaha pengkondisian thermal dengan menyeleksi sinar matahari yang masuk ke dalam bangunan dengan menggunakan sun shading (pembayang matahari). Pada daerah tropis, pelindung terhadap matahari menjadi suatu hal yang penting (Lechner, 2007). Perlindungan terhadap matahari dapat dicapai melalui penggunaan vegetasi, elemen horisontal ataupun vertikal yang tidak tembus cahaya. Elemen horisontal yang menonjol pada sisi bangunan, sangat efektif digunakan pada sisi utara dan selatan untuk menahan sudut jatuh sinar matahari tinggi.

Solar shading merupakan elemen utama yang harus dipertimbangkan untuk meningkatkan target efisiensi energi pada bangunan (ES-SO, 2018). Walaupun demikian teknologi pengolahan solar shading masih terus berkembang hingga saat ini. Radiasi panas matahari dibagi menjadi beberapa kategori berdasarkan spektrumnya (ES-SO, 2018):

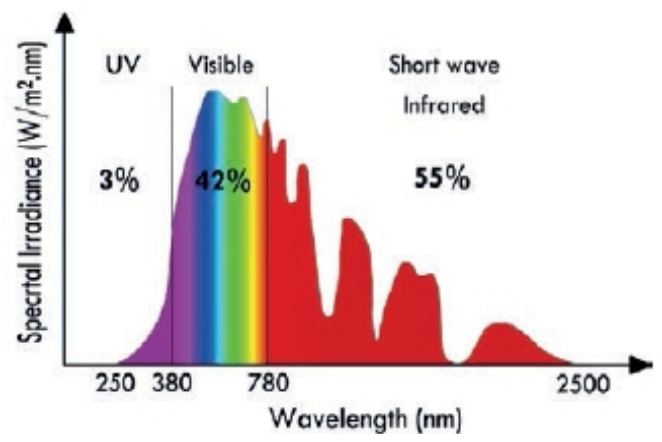

Gambar 1. Spektrum radiasi panas matahari

(Sumber: ES-S0, 2018)

a. Ultraviolet (UV): berkisar mulai $250 \mathrm{~nm}$ sampai $380 \mathrm{~nm}$, spektrum ini tidak terlihat oleh mata biasa dan bisa berbahaya jika diterima berlebihan.

b. Visible: berkisar antara $380 \mathrm{~nm}$ (violet) sampai $780 \mathrm{~nm}$ (red), spektrum ini dapat dilihat oleh retina manusia.

c. Short Wave Infrared (IR): berkisar antara $780 \mathrm{~nm}$ sampai $2500 \mathrm{~nm}$, spektrum ini tidak terlihat tetapi dapat dirasakan sebagai panas. 


\subsection{Kinerja material terhadap radiasi panas matahari}

Menurut (ES-SO, 2018), jika suatu permukaan menerima radiasi matahari, maka incident radiation $E$ akan terpencar menjadi tiga bagian, antara lain:

a. Bagian yang ditransmisikan melalui material ( )

b. Bagian yang direfleksikan oleh material $(\rho)$

c. Bagian yang diserap oleh material ( )

Sehingga berlaku rumus $+\rho+=100 \%$

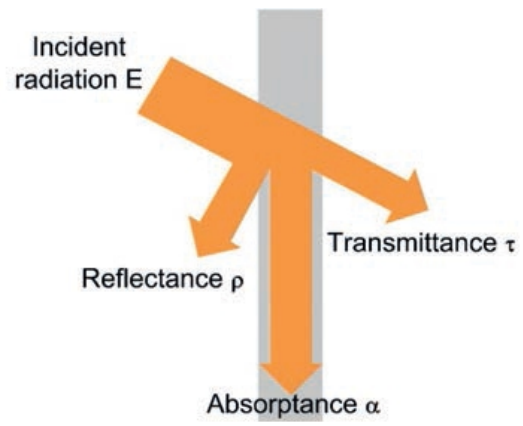

Gambar 2. Perilaku radiasi matahari saat kontak dengan material

(Sumber: ES-S0, 2018)

\subsection{Karakter thermal : $U$-Value, $R$-Value dan $K$-Value}

Definisi U-Value merupakan kehilangan panas (thermal losses) yang melalui jendela. Untuk kaca single, koefisien ini bergantung kepada U-value kaca, U-value bingkai/ kusen, perantara antara kaca dan kusen, luas area kaca dan kusen serta besaran keliling kaca. Hubungan ini ditunjukkan oleh rumus:

$$
U w=\frac{A_{g} U_{g}+A_{f} U_{f}+I_{g} \psi_{g}}{A_{g}+A_{f}}
$$

Semakin rendah $U$-value $\left(\mathrm{W} / \mathrm{m}^{2} \mathrm{~K}\right)$, maka semakin baik insulasi jendela tersebut. Untuk $\mathrm{R}$-Value, merupakan resisten panas (thermal resistance). Nilai R-value bergantung pada air permeability dari material.

K- Value merupakan nilai dari kemampuan bahan dalam menghantarkan panas. Semakin rendah nilai K-Value maka semakin besar kemampuan bahan dalam menginsulasi panas.

\section{$2.4 \quad$ Metode}

Penelitian ini menggunakan metode eksperimental virtual untuk membantu mempersingkat waktu dan mempermudah dalam melakukan kegiatan penelitian, termasuk pengamatan dan analisis karena ukuran obyek yang digunakan adalah 1:1 (ukuran sebenarnya). Kegiatan penelitian ini dimulai dengan tahapan survey literatur dan survey lapangan untuk memperoleh data fisik objek studi kasus. Gedung baru pascasarjana Unisma merupakan objek yang digunakan dalam studi kasus kali ini. Gedung baru pascasarjana Unisma merupakan salah satu gedung baru yang dibangun pada kompleks Unisma. Gedung ini berbentuk persegi panjang dengan dimensi $25 \mathrm{~m} \mathrm{x}$ $35,75 \mathrm{~m}$. Gedung ini terdiri dari tujuh lantai, untuk lantai dua sampai enam, difungsikan sebagai kantor administratif pasca dan ruang-ruang perkuliahan. Sedangkan tujuh atau lantai paling atas, difungsikan sebagai hall/ ruang pertemuan. Untuk material fasad yang 
digunakan pada gedung ini tergolong modern. Hal ini terlihat dari penggunaan kaca reflektif pada seluruh jendela eksterior gedung. Ketinggian antar lantai 4m.

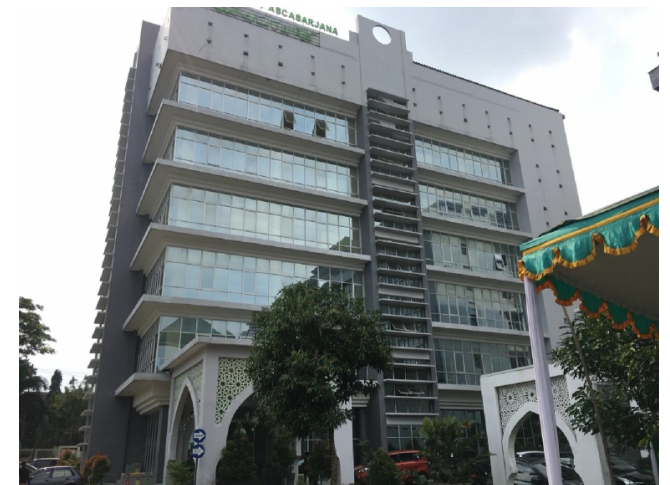

Foto eksterior objek

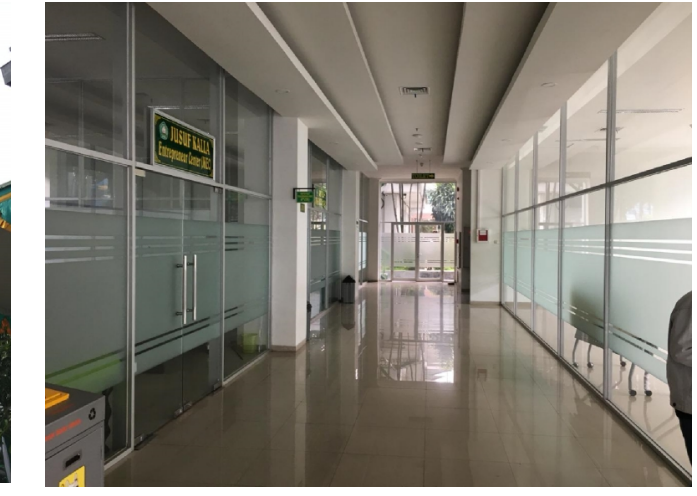

Foto interior objek

Gambar 3. Foto eksisting Gedung Baru Pascasarjana Unisma

Tahapan survey literature dilakukan utnuk menentukan parameter solar shading, baik bentuk, ukuran maupun material dan thermal propertiesnya. Dari hasil survey literatur (Kamal, 2010) ditemukan tiga jenis solar shading: movable opaque, louvre dan fixed. Dari tiga jenis solar shading yang diperoleh, ada dua jenis tipe solar shading yang akan dipilih sebagai parameter alternatif desain yang akan dimodifikasi. Berdasarkan kemampuan program simulasi, maka jenis louvre dan fixed dipilih untuk digunakan pada penelitian ini. Dimensi solar shading mengikuti dimensi jendela eksisting.

Parameter lain yang akan digunakan yaitu jenis material. Berdasarkan hasil survey literatur dan pengamatan lapangan ada beberapa jenis material yang biasa digunakan untuk solar shading, antara lain: beton, aluminium dan kayu.

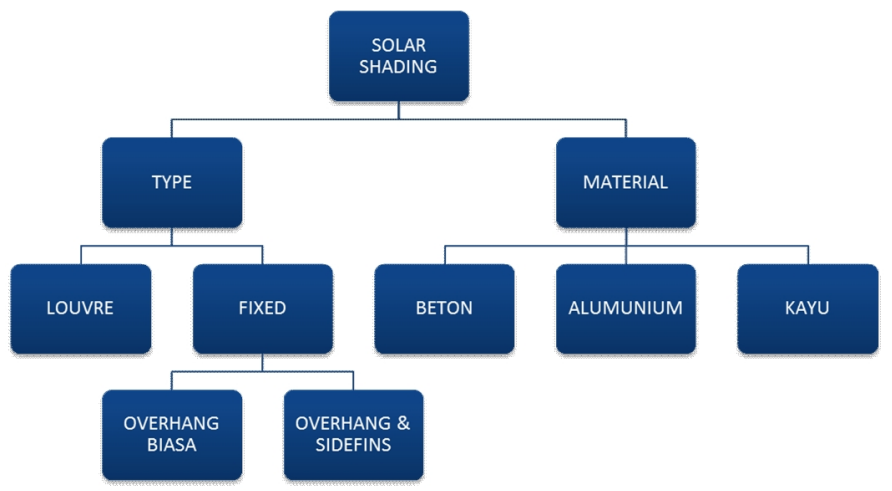

Gambar 4. Kategori parameter tipe dan material solar shading

Model simulasi dibuat sederhana untuk mengurangi terjadinya error dan mengurangi beban running time (Dewi, Huang, \& Nugroho, 2013). Permodelan awal dilakukan menggunakan Google Sketchup, dan Solver Engine untuk simulasi menggunakan Energyplus 8.3. Data iklim yang digunakan sebagai input simulasi merupakan data iklim per menit kota Malang tahun 2016 yang sudah dianalisis dan diolah menjadi file data iklim untuk menjalankan simulasi.

Langkah pertama dalam tahapan simulasi dan analisis adalah melakukan simulasi pada model dasar atau eksisting model. Base case model atau model dasar merupakan model prototype dari objek yang dibuat dalam program menyerupai objek asli baik ukuran dan material yang digunakan. Tidak ada modifikasi parameter baik desain tipe 
solar shading maupun material yang diaplikasikan pada model dasar ini. Model simulasi dibuat dengan beberapa penyederhanaan. Model dasar memiliki desain fixed overhang 0,8 $\mathrm{m}$ dengan material beton. Tahapan berikutnya adalah pembuatan dan simulasi alternatif model dengan mengkombinasikan parameter tipe dan material yang digunakan.

Ada delapan model alternatif desain yang dibuat dan dianalisis pada penelitian ini. Model alternatif desain tersebut diperoleh dari kombinasi parameter tipe dan material pada gambar Tabel 1.

Tabel 1. Parameter modifikasi dan thermal properties

\begin{tabular}{|c|l|l|c|c|c|c|}
\hline $\begin{array}{c}\text { Kode } \\
\text { Model }\end{array}$ & \multicolumn{1}{|c|}{ Tipe } & Material & $\begin{array}{c}\text { D } \\
(\mathbf{m})\end{array}$ & $\begin{array}{c}\text { K-Value } \\
(\mathbf{W} / \mathbf{m K})\end{array}$ & $\begin{array}{c}\mathbf{R}-\text {-Value } \\
\left(\mathbf{m}^{\mathbf{2}} \mathbf{K} / \mathbf{W}\right)\end{array}$ & $\begin{array}{c}\text { U-value } \\
\left(\mathbf{W} / \mathbf{m}^{\mathbf{2}} \mathbf{K}\right)\end{array}$ \\
\hline \multirow{2}{*}{$\mathbf{A}$} & \multirow{2}{*}{ Overhang } & Alumunium & 0,1 & 160 & 0,0006 & 1600 \\
\hline & & Kayu & 0,02 & 0,17 & 0,1176 & 8,5 \\
\hline \multirow{2}{*}{$\mathbf{B}$} & \multirow{2}{*}{ Louvre } & Beton & 0,1 & 0,72 & 0,1389 & 7,2 \\
\cline { 3 - 7 } & & Alumunium & 0,1 & 160 & 0,0006 & 1600 \\
\cline { 3 - 7 } & & Kayu & 0,02 & 0,17 & 0,1176 & 8,5 \\
\hline \multirow{2}{*}{$\mathbf{C}$} & \multirow{2}{*}{ Overhang\&sidefins } & Beton & 0,1 & 0,72 & 0,1389 & 7,2 \\
\cline { 3 - 7 } & & Alumunium & 0,1 & 160 & 0,0006 & 1600 \\
\cline { 3 - 7 } & & Kayu & 0,02 & 0,17 & 0,1176 & 8,5 \\
\hline
\end{tabular}

\section{Hasil dan Pembahasan}

Hasil simulasi model dasar untuk nilai solar gain exterior window ditunjukkan oleh Error! Reference source not found..

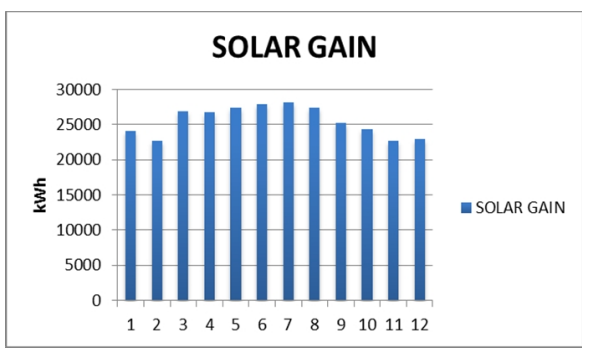

Gambar 5. Hasil simulasi solar gain pada model dasar

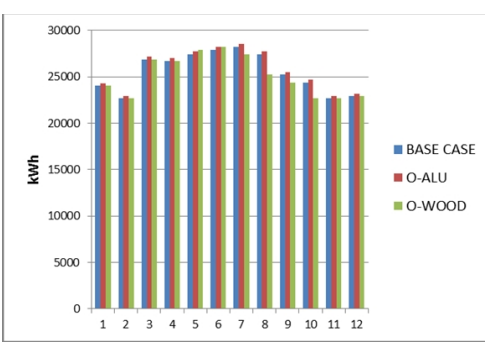

A

Base case-fixed overhang

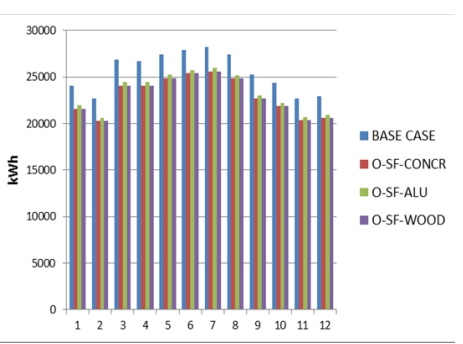

B

Base case-fixed overhang \& sidefins

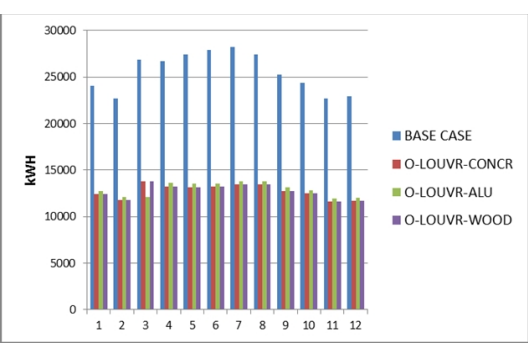

C

Base case- fixed overhang \& louvre

Gambar 6. Hasil simulasi desain solar shading dan material

Hasil simulasi pada Gambar 6 menunjukkan bahwa desain solar shading yang hanya diletakkan pada tepi atas (fixed overhang) dan samping bukaan jendela (sidefins) tidak memberikan pengaruh yang signifikan terhadap penurunan solar gain pada bangunan. Penurunan solar gain dengan penggunaan fixed overhang rata-rata hanya 
mencapai $7-10 \%$ dari solar gain semula. Sedangkan pada penggunaan louvre penurunan maksimal untuk nilai solar gain mampu mencapai 52\%.

Jenis material yang digunakan tidak membawa perubahan yang cukup berarti bagi target penurunan solar shading. Hal ini dapat dilihat pada ketiga desain solar shading. Perbedaan yang terjadi kurang lebih sekitar 3,8\%. Penggunaan material kayu dengan nilai konduktivitas termal yang hampir sama dengan beton, yaitu 8,5 W/mK dan 7,2 $\mathrm{W} / \mathrm{mK}$, memberikan hasil yang sama terhadap penurunan solar gain di masing-masing bentuk dan tipe solar shading. Penggunaan material alumunium, yang diambil dari hasil survey literatur pada beberapa bangunan di luar Indonesia, bahkan memberikan nilai solar gain yang lebih besar dibandingkan kondisi eksisting. Hal ini dikarenakan nilai konduktivitas thermal alumunium yang cukup tinggi sehingga R- Value nya menjadi sangat rendah.

\section{Simpulan}

Dari hasil dan analisis dalam penelitian ini dapat disimpulkan bahwa, pemilihan desain (bentuk dan tipe) solar shading lebih berpengaruh terhadap penurunan solar gain dibanding dengan penggunaan perbedaan jenis material. Penurunan nilai solar gain terbesar $(52,73 \%)$ diperoleh melalui model C (penggunaan tipe solar shading : fixed overhang-louvre) pada penggunaan material beton dan kayu.

Nilai R-Value bahan juga memberikan pengaruh terhadap nilai solar gain jendela. Semakin besar R-Value sebuah materi maka semakin baik nilai tahanan termal materi tersebut. Hal ini terbukti dari hasil penelitian yang sudah dilakukan bahwa alumunium memberikan nilai R-Value yang paling rendah dan menaikkan besaran nilai solar gain yang seharusnya diharapkan bisa menjadi lebih rendah. Dalam penelitian kali ini nilai solar gain pada penggunaan kayu bahkan menaikkan beban solar gain sebesar 1,14\%. Dapat dilihat bahwa untuk daerah tropis seperti Indonesia, penggunaan alumunium sebagai material solar shading pada bangunan tidak disarankan.

\section{Daftar Pustaka}

Dewi, C. P. (2013). Double Skin Façade Strategy in Reducing Cooling Energy Demand for Energy Efficiency. National Central University, Taiwan.

Dewi, C. P., \& Bakhtiar, A. (2017). Efektifitas Kinerja Double Skin Fasade-Green Wall terhadap Efisiensi Energi Pendinginan Bangunan. Jurnal RUAS, 2.

Dewi, C. P., Huang, R.-Y., \& Nugroho, A. M. (2013). Strategi Double Skin Fasade pada Bangunan Kampus National Central University dalam Menurunkan Kebutuhan Energi Pendinginan. Jurnal RUAS.

ES-SO. (2018). Solar shading for Low Energy and Healthy Buildings. European Solar shading Organization.

Kamal, M. A. (2010). A Study on Shading of Buildings as a Preventive Measure for Passive Cooling and Energy Conservation in Buildings. International Journal of Civil \& Environmental Engineering, 10 No 06.

Lechner, N. (2007). Heating, Cooling, Lighting Metode Desain Untuk Arsitektur. Jakarta: PT Raja Grafindo Persada.

Lubab Fahmi, E. (2018). Shading device. Retrieved from https://www.scribd.com/document/327359926/560b8e1f7cff4EMIL-LUBAB-

FAHMI-1451010018-Shading-Devices

Prasetyo, Y. H. (2014). Kinerja Bangunan Desain Pasif Berdasarkan Simulasi Ecotect Dan Pengukuran Lapangan Studi Kasus: Bangunan Konvensi "Grha Wiksa Praniti" Bandung Building Performance of Passive Design Based on Ecotect Simulation and 
Field Measurement Case Study : Convention Center Building "Grha Wiksa Praniti" Bandung. Jurnal Permukiman, 9 No.1, 41-53.

Prianto, E. (2007). Pemanasan Global Dan Konsep Rumah Hemat Energi. Retrieved from http://www.energiterbarukan.net 